\title{
ANALISIS TEKNIK DAN KUALITAS TERJEMAHAN KALIMAT YANG MEREPRESENTASIKAN TUTURAN MENGANCAM MUKA NEGATIF PADA THE ADVENTURES OF SHERLOCK HOLMES
}

\author{
Maftuchah Dwi Agustina ${ }^{1}$; M. R. Nababan² Djatmika $^{2}$ \\ ${ }^{1}$ Magister Linguistik Program, Universitas Sebelas Maret, Surakarta, Indonesia \\ ${ }^{2}$ Professor at Universitas Sebelas Maret, Surakarta, Indonesia \\ uwiequw@gmail.com
}

\begin{abstract}
There are a lot of translated novel spread on the book stores. It happens because it has more interesting plots comparing to the local novel and this demand made the translation important. Eventhough as a translation product, it still has to be able to give the same taste toward the target reader. The object of this study is aimed at: analyzing the types of FTA in The Adventures of Sherlock Holmes and its translation, analyzing the translation techniques and determining the impact in terms of accuracy, acceptability, and readability.

This research is descriptive qualitative and focuses on a single case. The data in this study were sentences representing the FTA found in The Adventures of Sherlock Holmes and its translations. The data in the form of informant were taken from raters who assessed the translation quality. This research uses purposive sampling technique. The data collecting techniques used in this research are document analysis and FGD.

There are 21 types of FTA found. There were 15 techniques applied with the frequency 1028 times. They are: established equivalent, variation, reduction, amplification, adaptation, transposition, pure borrowing, discursive creation, linguistic compression, modulation, compensation, generalization, literal, naturalized borrowing, and linguistic amplification. Technique that has positive impact are: established equivalent, amplification, reduction, pure borrowing, compensation, adaptaion, and linguistic compression. Technique that has negative impacts are: literal and discursive creation.
\end{abstract}

Keywords: speech act, face threatening acts, translation techniques, accuracy, acceptabilty, readabilty.

\section{PENDAHULUAN}

Kumpulan cerita pendek terjemahan semakin dinikmati oleh pembaca karena topiknya berragam dan alur ceritanya lebih dinamis dan tidak hanya membahas tentang cinta seperti kebanyakan karya lokal, tetapi juga tentang imajinasi, dan petualangan seri seorang detektif. Lain halnya dengan karya lokal yang kebanyakan hanya bercerita tentang cinta dengan alur yang sangat mudah di tebak. 
Terkait dengan penerbitan karya terjemahan yang semakin banyak, kegiatan penerjemahan menjadi hal yang penting. Sekalipun para penerjemah tersebut mampu memberikan terjemahan yang baik, namun permasalahan kerap kali muncul di dalamnya. Salah satu problematika penerjemahan adalah perihal kualitas terjemahan mengingat teks yang tertuang pada karya sastra berbeda dengan teks yang umumnya dijumpai oleh penerjemah. Tidak semua orang, bahkan yang mengaku sebagai penerjemah sekalipun mampu menerjemahkan dengan baik. Sebab, yang dibutuhkan bukan saja kemahiran berbahasa asing, tetapi juga kemampuan menginterpretasi dan memahami teks untuk mendapatkan hasil terjemahan yang bermutu dan "bernyawa" atau kemampuan menginterpretasi atau menafsirkan dan memahami teks demi mendapatkan "roh" cerita secara utuh dari pesan dalam bahasa sumber (http://www.goodreads.com/topic/show/90241-penerjemah).

Dalam menerjemahkan suatu karya sastra, tidak hanya mensyaratkan transmisi informasi di antara dua bahasa. Penerjemah sastra harus memperhitungkan "gereget, emosi, dan rasa suatu karya dalam versi bahasa orisinal; bentuk estetis yang dipakai pengarang orisinal; juga setiap informasi yang terkandung dalam pesan." (http://inisiatifpenerjemahansastra.org/tulisan-writing/sastra-terjemahan-kita/). Selain harus menguasai bahasa sumber (Bsu) dan bahasanya sendiri dengan sama baiknya belum tentu menjamin mutu terjemahannya. Menurut Nababan (2003: 12-13) ilmu penerjemahan termasuk ilmu interdisipliner yakni ilmu yang menerima sumbangan dari ilmu-ilmu lain, seperti linguistik, psikolinguistik, pragmatik, ilmu komunikasi, filologi dan lain sebagainya.

Menurut Levinson (1983), pragmatik merupakan telaah mengenai relasi antara bahasa dengan konteks yang merupakan dasar dalam pemahaman bahasa. Ini 
menunjukkan bahwa ketika seseorang berkomunikasi, maka dia harus mengetahui fungsi bahasa yang digunakan untuk mencapai pemahaman dari mitra tuturnya. Dalam perkembangannya, pragmatik memiliki aspek-aspek yang berkaitan erat dengan penerjemahan. Aplikasi pendekatan pragmatik dalam penerjemahan yang banyak diterapkan adalah dalam percakapan/tuturan, mengingat keduanya mengandung maksud tersendiri berdasarkan situasi tutur tertentu mencakup penutur dan mitra tutur; konteks; tujuan; waktu dan tempat.

Melalui bahasa, setiap penutur berinteraksi dengan lawan tutur yang lain yang senantiasa menjaga dan bekerjasama untuk menghormati muka masing-masing. Penutur menyadari bahwa muka tersebut dimiliki oleh mitra tuturnya. Dikatakan oleh Brown dan Levinson (1987:65-68) bahwa konsep tentang muka ini bersifat universal, dan secara alamiah terdapat berbagai tuturan yang cenderung merupakan tindakan yang tidak menyenangkan yang disebut Face Threatening Act (tindakan mengancam muka) yang disingkat menjadi FTA. Oleh sebab itu, kajian ini perlu diteliti agar setiap peserta tutur dapat menghindari tindakan mengancam muka dalam berkomunikasi karena tindakan tersebut dapat merugikan bahkan menjatuhkan harga diri lawan tutur. Sehubungan dengan itu, penutur seharusnya menggunakan strategi kesopanan tertentu untuk mengurangi risiko atau akibat kurang menyenangkan dari tuturannya. Muka 'face' menurut Brown dan Levinson (1987) dapat dibedakan menjadi dua macam yaitu muka negatif dan muka positif. Menurut Brown dan Levinson (1987: 67) sejumlah tindakan memang dapat mengancam muka baik muka negatif maupun muka negatif lawan tutur. 


\section{TEORI DAN METODOLOGI}

\section{Pengertian Penerjemahan}

Secara umum, penerjemahan asalah proses penyampaian pesan dari bahasa sumber $(\mathrm{BSu})$ ke dalam bahasa sasaran (BSa). Newmark (1988:5) mendefinisikan penerjemahan sebagai "renderring meaning of a text into another language in the way that author intended the text". Definisi tersebut mengandung arti bahwa penerjemahan merupakan sebuah proses untuk menerjemahkan sebuah makna ke dalam bahasa lain dengan yang dimaksud oleh penulis. Selanjutnya nida dan Taber (1982) menyatakan bahwa "translating consists of reproducing in the receptor language the closest natural equivalent of the source language message, first in terms of meaning and secondly in terms of style." Definisi ini menunjukkan adda empat hal penting yang menjadi pokok permasalahan dalam produk terjemahan itu sendiri, yaitu: masuk akal, setia makna dan gaya.

\section{Teknik Penerjemahan}

Pendapat Molina dan Albir (2002) terkait teknik penerjemahan adalah prosedur untuk menganalisis dan mengklasifikasikan bagaimana kesepadanan berlangsung dan diterapkan. Menurut Molina dan Albir, terdapat lima karakteristik dalam teknik penerjemahan; teknik penerjemahan mempengaruhi hasil terjemahan, teknik diklasifikasikan dengan perbandingan pada teks $\mathrm{BSu}$ dengan $\mathrm{BSa}$, teknik berada pada tataran mikro, teknik tidak saling berkaitan tetapi berdasarkan konteks tertentu dan teknik bersifat fungsional.

Teknik penerjemahan menurut Molina dan Albir (2002) diklasifikasikan menjadi 18 jenis teknik. Teknik-teknik tersebut antara lain: adaptasi, amplifikasi, 
peminjaman, kalke, kompensasi, deskripsi, kreasi diskursif, pemadanan lazim, generalisasi, amplifikasi linguistik, kompresi linguistik, harfiah, modulasi, partikularisasi, reduksi, subtitusi, transposisi, dan variasi.

\section{Penilaian Kualitas Terjemahan}

Tujuan utama seorang penerjemah dalam menerjemahkan adalah untuk menghasilkan terjemahan yang berkualitas (tercapainya keakuratan, keberterimaan dan keterbacaan). Sebagai senuah produk, terjemahan tentunya mempunyai tingkatan kualitas yang bisa ditentukan oleh berbagai faktor. Pada umumnya, kualitas suatu terjemahan bisa diukur dari faktor keakuratan, keberterimaan, dan keterbacaan sebagaimana parameter kualitas terjemahan yang telah dikemukakan oleh Nababan, Nureni, dan Sumardiono (2012).

\section{Tindak Tutur (Speech Act)}

Teori tindak tutur adalah pandangan yang memusatkan perhatian pada penggunaan bahasa dalam menyampaikan maksud dan tujuan pembicaraan. Dalam berkomunikasi, penutur maupun mitra tutur harus saling memahami kaidah-kaidah bahasa yang mengatur hal tersebut agar kegiatan tindak tutur dapat berjalan dengan baik.

Searle (1969: 24-25) berpendapat bahwa semua komunikasi linguistik mengandung mitra tutur. Artinya, komunikasi bukan sekedar lambang, kata atau kalimat yang berwujud perilaku tindak tutur. Searle (1969) dan Austin (1962) memandang tindak tutur yang dilangsungkan dengan kalimat performatif oleh Austin dirumuskan sebagai tiga peristiwa tindakan yang berlangsung, yang diwujudkan oleh penutur, yaitu 
tindak lokusi (locutionary acts), ilokusi (illocutionary acts) dan perlokusi (perlocutionary acts). Dari ketiga tindak tutur yang dikemukakan oleh Searle dan Austin di atas, kemudian Searle (1969) mengembangkan teori tindak tutur yang berpusat padda tindak ilokusi tersebut berdasarkan pada tujuan dari tindakan pandangan penutur menjadi lima sub bagian, yakn asertif (assertives), direktif (directives), komisif (commisives), ekspresif (expressives) dan deklaratif (declaratives).

\section{Konsep Tentang Muka dan Tuturan Mengancam Muka}

Brwon dan Levinson (1987) menjelaskan konsep tentang muka "face” penting dalam kajian penggunaan bahasa sebagai alat komunikasi. Muka adalah "face" atau citra diri yang dimiliki oleh setiap orang yang senantiasa dijaga, dihormati dan tidak dilanggar dalam proses petuturan antar peserta tutur. tindakan mengancam muka adalah tindak tutur yang secara alamiah berpotensi untuk melukai citra atau muka "face" lawan tutur dan oleh karena itu dalam pengutaraannya harus menggunakan strategistrategi tertentu.

Menurut Brown dan Levinson (1987) ada dua tipe muka, yaitu muka negatif dan muka positif. Muka negatif yaitu: keinginan individu agar setiap keinginannya tidak dihalangi oleh pihak lain. Sedangkan muka positif yaitu keinginan setiap penutur agar dia dapat diterima atau disenangi oleh pihak lain. Secara alamiah terdapat berbagai tuturan yang cenderung merupakan tindakan yang tidak menyenangkan yang disebut Face Threatening Act yang kemudian akan disingkat menjadi FTA. FTA yang mengancam muka negatif lawan tutur menurut Brown dan Levinson antara lain: (1) Tuturan yang mengakibatkan lawan tutur menyetujui atau menolak melakukan sesuatu, seperti: ordering, requesting, suggesting dan lain sebagainya. (2). Tuturan yang 
mengungkapkan upaya penututur melakukan sesuatu terhadap lawan tutur untuk menerima atau menolak tindakan tersebut, seperti: offering dan promising. (3). Tuturan yang mengungkapkan keinginan penutur untuk melakukan sesuatu terhadap lawan tutur atau apa yang dimiliki oleh lawan tutur, seperti: complimenting, showing anger, expressing of strong (negative) feelings.

\section{METODOLOGI}

Penelitian ini merupakan penelitian deskriptif kualitatif. Dikatakan demikian karena penilitian ini menitikberatkan pada data yang berupa kata-kata, kalimat, atau gambar yang memiliki arti lebih dari pada sekedar angka atau frekuensi (Sutopo, 2002:35). Penelitian ini juga disebut penelitian dasar bidang penerjemahan, berbentuk terpancang dan berkasus tunggal.

Masalah yang akan diteliti dalam penelitian ini adalah terjemahan tuturan mengancam muka negatif dalam kumpulan cerita pendek The Adventures of Sherlock Holmes beserta terjemahannya. Untuk mendapatkan data dalam penelitian ini penulis menggunakan pendekatan pragmatik, sehingga penulis bisa mendapatkan klasifikasi data yang rinci. Selain itu, teori penerjemahan juga diterapkan untuk menganalisis teknik-teknik penerjemahan yang digunakan untuk mengukur kualitas terjemahan dilihat dari keakuratan, keberterimaan dan keterbacaan. Metode etnografi juga diaplikasikan oleh peneliti untuk proses pengumpulan data dari informan dengan secara langsung turun ke lapangan.

Sumber data dalam penelitian ini ada dua, yaitu data primer dan data sekunder. Data primer termasuk semua tuturan mengancam muka negatif yang terdapat pada The Adventures of Sherlock Holmes dan terjemahannya serta data ynag diperoleh dari hasil 
kuesioner dan FGD. Data sekunder adalah segala informasi yang terkait dengan novel The Adventures of Sherlock Holmes beserta terjemahannya.

Teknik cuplikan (sampling) pada penelitian ini bersifat purpossive sampling, artinya data yang dipilih dan dikumpulkan berdasarkan pendekatan teori yang digunakan, rater dan informan yang dilibatkan juga memiliki kriteria-kriteria tertentu. Teknik pengumpulan data merupakan hal yang dianggap penting dan dilakukan dengan cara mengkategorikan, mengklasifikasikan, memverivikasi dan menganilisis. Langkah yang diambil dalam penelitian ini dalah teknik analisis dokumen, kuesioner, dan FGD.

Langkah pertama yang diambil dalam teknik analisis data adalah analisis domain. Langkah ini bertujuan untuk memisahkan mana yang data dan yang bukan data. Selanjutnya adalah analisis taksonomi, pada tahapan ini data yang telah didapat kemudian diklasifikasikan berdasarkan jenis tuturan mengancam muka negatif. Tahap ke tiga dalam analisis data adalah analisis komponensial, yaitu menganalisis teknikteknik pernerjemahan serta hubungannya dengan FTA dan dampaknya terhadap kualitas terjemahan. Langkah analisis terakhir adalah analisis tema budaya. Analisis ini dilakukan untuk menemukan hubungan-hubungan yang terdapat pada domain-domain yang dianalisis sehingga membentuk kesatuan yang holistis, terpola dalam suatu complex pattern yang akhirnya menampakkan ke permukaan tentang tema-tema atau faktor yang paling mendominasi domain tersebut dan mana yang kurang mendominasi.

\section{Temuan Penelitian dan Pembahasan}

Bab ini memaparkan hasil penelitian dan pembahasan. Hasil penelitian meliputi temuan jenis tuturan mengancam muka negatif yang sebelumnya telah diklasifikasikan dalam speech act, penggunaan teknik penerjemahan dan kualitas 
terjemahan. Selanjutnya, pada bagian pembahasan akan memuat beberaa evaluasi yang mencakup: jenis tuturan mengancam muka negatif, penerapan teknik penerjemahan, pengaruh penerapan teknik penerjemahan terhadap kualitas terjemahan dan analisis tema budaya.

\section{Hasil Penelitian}

Jenis Tuturan Mengancam Muka Negatif.

Berdasarkan teori yang ditawarkan oleh Brown dan Levinson (1987), ditemukan sebanyak 165 data penelitian, dan dikemukakan oleh penutur sebanyak 106, 59 sisa datanya dikemukakan oleh mitra tutur. Tahap berikutnya, keseluruhan data yang ditemukan dikelompokkan menurut jenis tindak tuturnya.

\section{Tuturan Mengancam Muka Negatif yang Dilakukan oleh Penutur}

\begin{tabular}{|l|l|l|l|l|}
\hline No & \multirow{2}{*}{ Jenis Speech Act } & Jenis FTA & Jumlah & Presentase \\
\hline \multirow{4}{*}{1.} & \multirow{2}{*}{ Direktif } & Bertanya & 55 & $52 \%$ \\
\cline { 3 - 5 } & Memerintah & 10 & $9,4 \%$ \\
\cline { 3 - 5 } & Meminta & 9 & $8,4 \%$ \\
\cline { 3 - 5 } & Memperingatkan & 7 & $6,7 \%$ \\
\cline { 3 - 5 } & Menantang & 2 & $1,8 \%$ \\
\cline { 3 - 5 } & $\begin{array}{l}\text { Memaksakan } \\
\text { kehendak }\end{array}$ & 1 & $0,9 \%$ \\
\cline { 3 - 5 } & Mengundang & 1 & $0.9 \%$ \\
\hline 2. & Asertif & Menyangkal & 1 & $0,9 \%$ \\
\hline 3. & Komisif & Mengancam & 5 & $4,8 \%$ \\
\cline { 3 - 5 } & Berjanji & 2 & $5,7 \%$ \\
\hline 4. & Ekspresif & Mengejek (mocking) & 6 & $3,8 \%$ \\
\cline { 3 - 5 } & Meminta maaf & 4 & $1,9 \%$ \\
\cline { 3 - 5 } & Mengeluh & 2 & $10,9 \%$ \\
\cline { 3 - 5 } & Menghina (insulting) & 1 & \\
\hline \multirow{2}{*}{ Jumlah } & & 106 & \\
\hline
\end{tabular}

\section{Tindak Tutur Direktif}

Bertanya merujuk pada tuturan mengancam muka untuk mengajukan sebuah pertanyaan.

Contoh (088):

Ryder: "Oh, sir, can you tell me where it went to?" 
Ryder: “Oh, tuan, bisakah anda memberitahukan di mana angsa itu?

Holmes: "It came here."

Memerintah (commanding), tuturan ini merujuk pada tuturan mengancam muka negatif yang berfungi memerintah. Terdapat 10 data tuturan dengan jenis ini.

Contoh (027):

Police agent: "Well, would you please, sir, march upstairs, where we can get a cab to carry your Highness to the police-station?"

Agen polisi: "Tuan, bersediakah Anda berjalan ke atas, di mana kami dapat mencarikan sebuah kereta kuda untuk membawa paduka ke kantor polisi'”.

John Clay: "That is better".

Meminta (requesting) pada penelitian ini merujuk pada tuutran yang berfungsi meminta. Tuturan ini lebih halus dibandingkan dengan memerintah. Dari seluruh data penelitian, terdapat 10 data dengan jenis ini.

Contoh (001)

Holmes: "A nice little brougham and a pair of beauties. A hundred and fifty guineas a piece. There's money in this case, Watson, if there is nothing else."

Watson: "I think that I had better go, Holmes."

Watson: "Ku kira lebih baik aku pergi, Holmes."

Memperingatkan (warning) menurut Brown dan Levinson juga merupakan salah satu jenis tuturan FTA. Terdapat 7 data tuturan jenis memperingatkan yang dilakukan oleh penutur.

Contoh (025):

John Clay: "I beg that you will not touch me with your filthy hands...."

John Clay: "Ku minta kau tak menyentuhku dengan tanganmu yang kotor itu.."

Police agent: "All right"

Menantang (challenging) merujuk pada ajakan berkelahi atau bertaruh karena penutur merasa ia lebih kuat atau mampu dibanding dengan mitra tuturnya. Terdapat 2 data dengan jenis tuturan ini.

Contoh (077)

Holmes: "You'll never persuade me to believe that."

Seller: "Will you bet, then?"

Penjual: "kau mau bertaruh?"

Memaksakan kehendak (insisting) dalam penelitian ini, merujuk pada tuturan yang bersifat mendesak, berkali-kali menyuruh atau meminta dengan paksa mitra tutur agar melakukan apa yang dikehendaki oleh penutur.

Contoh (046):

The coroner: "I am afraid that I must press it."

Koroner: "Saya harus memaksa anda.

James: "It is really impossible for me to tell you..."

Mengundang (inviting), mengundang memiliki potensi bagi penutur untuk kehilangan mukanya. Dalam penelitian ini, mengundang hanya memiliki 1 frekuensi kemunculan.

Contoh (138): 
Holmes: "I had hoped, that you would have joined us in a friendly supper."

Holmes: "Saya berharap, anda dapat bergabung dengan makan malam yang bersahabat ini."

Lord. St. Simon: "I think that there you ask a little too much."

\section{Tindak Tutur Asertif}

Menyangkal (denying) merupakan tuturan untuk membantah, mengingkari, tidak mengakui atau tidak membenarkan ucapan penutur.

Contoh (103):

Holmes: "You have done wisely. But have you told me all?"

Helen: "Yes, all."

Holmes: "Miss Roylot, you have not, you are screening your stepfather."

Holmes: "Nona Roylot, belum. Anda melindungi ayah tiri anda."

\section{Tindak Tutur Komisif}

Mengancam (threatening) tuturan jenis ini termasuk ke dalam FTA dikarenakan tuturan ini membuat mitra tutur tidak memiliki kebebasan untuk memilih dan menanggung tiap konsekuensi dari pilihan yang ia pilih.

Contoh (041)

Holmes: "I let you know then, that I have caught him!"

Mr. Windibank: "What? Where?”(Mr. Windibank hendak melarikan diri)

Holmes: "oh, it won't do-really it won't. There is no possible getting out of it, Mr. Windibank. It is quite too transparent..."

Holmes: "oh, tidak akan berhasil, tidak akan berhasil. Tidak mungkin selamat Tuan Windibank. Semuanya cukup transparan..."

Berjanji (promising) bertujuan untuk menyatakan kesediaan atau kesanggupan untuk berbuat sesuatu. Dua tuturan jenis ini dilakukan oleh penutur.

Contoh (092):

Ryder: "...I never went wrong before! I never will again. I swear it. I'll swear it on a bible...”

Holmes: "Get back into your chair!"

Ryder: "..Aku belum pernah melakukan kesalahan sebelumnya! Aku tak akan pernah melakukannya lagi. Aku bersumpah. Aku bersumpah atas nama Injil!..”

\section{Tindak Tutur Ekspresif}

Mengejek (mocking) tuturan ini merujuk pada tuturan yang bersifat merendahkan lawan bicaranya dan menimbulkan rasa tidak senang karea membuat mitra tutur kehilangan mukanya.

Contoh (147)

Holder: "You villain! You thief! How dare you touch that coronet?"

Holder: "Keparat kau! Pencuri! Beraninya kau menyentuh rangkaian itu!"

Holder: "You blackguard!"

Meminta maaf (apologizing) merupakan salah satu jenis tuturan mengancam muka negtif. Terdapat 4 data tuturan jenis ini yang dilakukan oleh penutur.

Contoh (053): 
Client: "I owe you an apology. I trust that I am not intruding..."

Klien: "Saya minta maaf. Saya harap saya tidak mengganggu...."

Holmes: "Come in!"

Mengeluh (complaining), sesuai dengan teori yang ditawarkan oleh Brown dan Levinson merupakan tuturan yang berpotensi untuk mencederai muka mitra tutur. Dalam penelitian ini, terdapat 12 data yang dituturkan oleh penutur.

Contoh (078):

(Ryder mendatangi kios tersebut dan menanyakan tentang angsa itu dan mendapatkan jawaban yang sama."

Ryder: "I've had enough of you and your geese."

Ryder: "Aku sudah muak denganmu dan angsa-angsamu."

Seller: "I wish you were all at the devil together..."

Menghina (insulting), tuturan ini merujuk pada tuturan yang berfungsi untuk memandang rendah mitra tutur.

Contoh (127)

Lord St. Simon: “.. I understand that you have already managed several delicate cases of this sort, sir, though I presume that they were hardly from the same class or society." Lord St. Simon: “..Saya mengerti bahwa anda telah menangani berbagai macam kasus rumit seperti ini walaupun saya menduga bukan berasal dari kelas sosial saya."

Holmes : "No, I am descending."

Tuturan Mengancam Muka Negatif yang Dilakukan oleh Mitra Tutur

\begin{tabular}{|c|c|c|c|c|}
\hline No & Jenis Speech Act & Jenis FTA & Jumlah & Presentase \\
\hline \multirow[t]{3}{*}{1} & \multirow[t]{3}{*}{ Direktif } & Memohon & 3 & $6 \%$ \\
\hline & & Menantang & 1 & $1,7 \%$ \\
\hline & & Meminta & 1 & $1,7 \%$ \\
\hline \multirow[t]{5}{*}{2} & \multirow[t]{5}{*}{ Ekspresif } & Mengeluh & 12 & $21 \%$ \\
\hline & & $\begin{array}{l}\text { Menghina } \\
\text { (insulting) }\end{array}$ & 3 & $6 \%$ \\
\hline & & Meminta maaf & 2 & $3,4 \%$ \\
\hline & & Menyesal & 1 & $1,7 \%$ \\
\hline & & Mengumpat & 1 & $1,7 \%$ \\
\hline \multirow[t]{4}{*}{3} & \multirow[t]{4}{*}{ Komisif } & Menolak (refusing) & 10 & $10 \%$ \\
\hline & & Mengancam & 6 & $10 \%$ \\
\hline & & Menolak (rejecting) & 3 & $6 \%$ \\
\hline & & Berjanji & 3 & $6 \%$ \\
\hline \multirow[t]{3}{*}{4} & \multirow[t]{3}{*}{ Asertif } & Menjawab & 8 & $13,5 \%$ \\
\hline & & Menyangkal & 4 & $6,8 \%$ \\
\hline & & Meledek & $\mathbf{1}$ & $1,7 \%$ \\
\hline \multicolumn{3}{|c|}{ Jumlah } & 59 & $100 \%$ \\
\hline
\end{tabular}

\section{Tindak Tutur Direktif}

Memohon (begging) merujuk pada tuturan yang bersifat meminta sesuatu dengan penuh rasa hormat. Terdapat 3 data dengan jenis tuturan ini.

Contoh (090): 
Holmes: "I see-her ladyship's waiting-maid. Well, the tempation of sudden wealth.." Ryder: "For God's sake, have mercy!

Ryder: 'Demi Tuhan, kasihanilah!"

Menantang (challenging) tuturan ini merujuk pada ajakan berkelahi atau bertaruh karena penutur merasa memiliki kemampuan lebih dibanding mitra tuturnya.

Contoh (021):

Mr. Merryweather: "Still, I confess that I miss my rubber..."

Holmes: "I think you will find play for a higher stake tonight that you have ever done yet, and the play will be more exciting...."

Holmes: "Aku yakin bahwa anda akan menemukan permainan dengan taruhan yang lebih tinggi malam ini, lebih tinggi dari permainan apapun yang pernah anda mainkan, dan permainan ini akan lebih menyenangkan..."

Meminta (requesting), merujuk pada tuturan yang berfungsi untuk meminta. Dari 10 data tuturan jenis ini, 9 diantaranya diungkapkan oleh penutur dan 1 sisanya diungkapkan oleh mitra tutur.

Contoh (017)

King: "You have but to name it."

Holmes: "This photograph!"

Homes: "Foto ini!"

King: "Irene's photograph!. Certainly, if you wish it."

Tindak Tutur Ekspresif

Mengeluh (complaining) selain diungkapkan oleh penutur, jenis ini juga diutarakan oleh mitra tuturnya yang berjumlah 2 data.

Contoh 1 (085):

Ryder: "My name is John Robinson."

Holmes: "No, no; the real name. It is always awkward doing business with an alias."

Holmes: "Bukan, bukan, nama yang asli. Selalu tidak nyaman melakukan pekerjaan dengan nama alias."

Menghina (insulting), merujuk pada tuturan yang berfungsi untuk memandang rendah lawan bicaranya. Terdapat 1 tuturan jenis ini yang diungkapkan oleh mitra tutur.

Contoh (132):

Holmes: "Quite so. Then I do not think that I need to detain you longer. I shall communicate with you."

Lord St. Simon: "Should you be fortunate enough to solve this problem."

Lord St. Simon: "Jika anda cukup beruntung karena telah memecahkan masalah ini."

Holmes: "I have solved it."

Meminta maaf (apologizing), tuturan jenis ini lebih banyak dilakukan oleh penutur, namun ada 2 data yang disampaikan oleh mitra tutur.

Contoh (082):

Ryder: "Who are you then? What do you want?"

Holmes: "You will excuse me, but I could not help overhearing the questions..."

Holmes: "Maafkan saya, tapi saya kebetulan mendengar pertanyaan.." 
Menyesal (regretting), dalam penelitian ini merujuk pada ungkapan yang menunjukkan rasa kecewa. Hanya terdapat 1 data dengan jenis tuturan ini.

Contoh (032):

Miss Sutherland: “...we got to the church first, and when the four-wheeler drove up we waited for him to step out, but he never did, and when the cabman got down from the box and looked there was no one there!"

Holmes: "It seems to me that you have been very shamefully treated,"

Holmes: " Tampaknya anda diperlakukan dengan sangat memalukan".

Miss Sutherland: "Oh, no, sir! He was too good and kind to leave me so...."

Mengumpat (swearing), tuturan ini diutarakan oleh peserta tutur ketika ia merasa tidak senang dan sering mengekspresikannya dengan mengumpat. Terdapat 1 data tuturan jenis ini.

Contoh (079):

Ryder: "I've had enough of you and your geese."

Seller: "I wish you were all at the devil together.."

Penjual: "Semoga kalian mampus..."

\section{Tindak Tutur Komisif}

Berjanji (promising) bertujuan untuk menyatakan kesediaan atau kesanggupan untuk berbuat sesuatu. Dari 5 data yang muncul, ada 3 data yang diungkapkan oleh mitra tutur.

Contoh 1 (006):

King: "By binding you both to absolute secrecy for two years; at the end of that time the matter will be of no importance. At present it is not too much to say that it is of such weight it may have an influence upon European history"

Holmes: "I promise".

Holmes: "Saya berjanjï"

Mengancam (threatening), tuturan jenis ini termasuk dalam FTA karena tuturan ini membuat mitra tuturnya merasa tidak memiliki pilihan dan dipaksa untuk menerima resiko dari pilihannya tersebut.

Contoh 1 (024):

(Holmes memukul pergelangan tangan John sehingga pistolnya jatuh).

Holmes: "It's no use, John Clay, you have no chance at all"

Holmes: "Tak ada gunanya, John Clay, kau tak bisa lari”.

John Clay: "so I see,"

Menolak (refusing), tuturan jenis ini berpotensi untuk mencederai muka lawan tutur. terdapat 10 data tuturan dengan jenis ini dan dilakukan oleh mitra tutur.

Contoh 1 (044):

The coroner: "What was the point upon which you and your father had this final quarrel?"

James: "I should prefer not to answer"

James: "Saya lebih suka tidak menjawabnya". 
Menolak (rejecting), tuturan ini merujuk pada sebuah bentuk penolakan ketika penutur tidak membenarkan, tidak menerima atau tidak mengabulkan permintaan lawan bicaranya. Dalam penelitian ini, terdapat 3 data jenis tuturan ini.

Contoh (005):

King: ".....I understand that this gentleman, your friend, is a man of honour and discretion, whom I may trust with a matter of the most extreme importance. If not, I should much prefer to communicate with you alone".

Holmes: "It is both, or none".

Holmes: "Kami berdua, atau tidak sama sekali”.

\section{Tindak Tutur Asertif}

Menjawab (answering) terdapat 8 data tuturan dengan jenis ini. Tuturan ini bisa dikategorikan FTA jika jawaban yang diberikan merupakan jawaban yang tidak ingin didengar oleh penanya.

\section{Contoh 1 (164):}

Holmes: "Where's your daughter?"

Mr. Rucastle: "It is for me to ask you that!,,"

Mr. Rucastle: "Akulah yang seharusnya bertanya.."

Menyangkal (denying), merupakan tuturn dengan fungsi membantah, mengingkari, tidak mengakui atau tidak membenarkan ucapan penutur. Terdapat 4 data tuturan jenis ini yang dilakukan oleh mitra tutur.

Contoh 1 (033):

Holmes: "It seems to me that you have been very shamefully treated,"

Miss Sutherland: "Oh, no, sir! He was too good and kind to leave me so..."

Nona Sutherland: “Oh, tidak, tuan!. Dia terlalu sopan dan baik hati untuk mencampakkan saya begitu saja seperti itu.."

Meledek (teasing), tuturan ini bersifat menggoda mitra tutur ketika penutur menyampaikan sesuatu yang serius namun malah dianggap lelucon. Dalam penelitian ini hanya ada 1 data dengan jenis tuturan ini.

Contoh (008):

King: "Five attempts have been made. Twice burglars in my pay ransacked her house. Once we diverted her luggage when she travelled. Twice she has been waylaid. There has been no result."

Holmes: "No sign of it?"

King: "Absolutely none."

Holmes: "It is quite little problem,"

Holmes: "Ini masalah yang cukup sepele."

Temuan Teknik Penerjemahan Kalimat yang Merepresentasikan Tuturan Mengancam Muka Negatif pada The Adventures of Sherlock Holmes

\begin{tabular}{|l|l|l|l|}
\hline No & Teknik Penerjemahan & $\begin{array}{l}\text { Jumlah } \\
\text { Data }\end{array}$ & Presentase \\
\hline 1 & Padanan lazim & 272 & $26,5 \%$ \\
\hline 2 & Variasi & 243 & $23,63 \%$ \\
\hline 3 & Reduksi & 197 & $19 \%$ \\
\hline 4 & Amplifikasi & 128 & $12,5 \%$ \\
\hline
\end{tabular}




\begin{tabular}{|l|l|l|l|}
\hline $\mathbf{5}$ & Adaptasi & $\mathbf{3 9}$ & $\mathbf{3 , 7 \%}$ \\
\hline $\mathbf{6 .}$ & Transposisi & $\mathbf{3 2}$ & $\mathbf{3 , 2 \%}$ \\
\hline $\mathbf{7 .}$ & Peminjaman murni & $\mathbf{2 8}$ & $\mathbf{2 , 7 \%}$ \\
\hline $\mathbf{8 .}$ & Kreasi diskursif & $\mathbf{2 1}$ & $\mathbf{2 \%}$ \\
\hline $\mathbf{9}$ & Kompresi linguistik & $\mathbf{1 8}$ & $\mathbf{1 , 8 \%}$ \\
\hline $\mathbf{1 0}$ & Modulasi & $\mathbf{1 6}$ & $\mathbf{1 , 6 \%}$ \\
\hline $\mathbf{1 1}$ & Kompensasi & $\mathbf{1 6}$ & $\mathbf{1 , 6 \%}$ \\
\hline $\mathbf{1 2}$ & Generalisasi & $\mathbf{1 1}$ & $\mathbf{1 , 0 7 \%}$ \\
\hline $\mathbf{1 3}$ & Harfiah & $\mathbf{4}$ & $\mathbf{0 , 4 \%}$ \\
\hline $\mathbf{1 4}$ & Peminjaman naturalisasi & $\mathbf{2}$ & $\mathbf{0 , 2 \%}$ \\
\hline $\mathbf{1 5}$ & Amplifikasi linguistik & $\mathbf{1}$ & $\mathbf{0 , 1 \%}$ \\
\hline Jumlah & $\mathbf{1 0 2 8}$ & $\mathbf{1 0 0 \%}$ \\
\hline
\end{tabular}

Kualitas Terjemahan Kalimat yang Merepresentasikan Tuturan Mengancam Muka Negatif pada The Adventures of Sherlock Holmes

Keakuratan

\begin{tabular}{|l|l|l|l|}
\hline No & $\begin{array}{l}\text { Tingkat } \\
\text { keakuratan }\end{array}$ & Jumlah & Presentase \\
\hline $\mathbf{1}$ & Akurat (3) & $\mathbf{1 3 3}$ & $\mathbf{8 0 , 7} \%$ \\
\hline $\mathbf{2}$ & $\begin{array}{l}\text { Kurang akurat } \\
(2)\end{array}$ & $\mathbf{2 6}$ & $\mathbf{1 5 , 7 \%}$ \\
\hline $\mathbf{3}$ & Tidak akurat (3) & $\mathbf{6}$ & $\mathbf{3 , 6 \%}$ \\
\hline Jumlah & $\mathbf{1 6 5}$ & $\mathbf{1 0 0 \%}$ \\
\hline
\end{tabular}

Keberterimaan

\begin{tabular}{|l|l|l|l|}
\hline No & $\begin{array}{l}\text { Tingkat } \\
\text { keberterimaan }\end{array}$ & Jumlah & $\begin{array}{l}\text { Prese } \\
\text { ntase }\end{array}$ \\
\hline $\mathbf{1}$ & Berterima (3) & $\mathbf{1 2 3}$ & $\mathbf{7 4 , 5 \%}$ \\
\hline $\mathbf{2}$ & $\begin{array}{l}\text { Kurang } \\
\text { berterima (2) }\end{array}$ & $\mathbf{4 1}$ & $\mathbf{2 5 \%}$ \\
\hline $\mathbf{3}$ & $\begin{array}{l}\text { Tidak } \\
\text { berterima (1) }\end{array}$ & $\mathbf{1}$ & $\mathbf{0 , 5 \%}$ \\
\hline Jumlah & $\mathbf{1 6 5}$ & $\mathbf{1 0 0 \%}$ \\
\hline
\end{tabular}

Keterbacaan

\begin{tabular}{|l|l|l|l|}
\hline $\begin{array}{l}\text { N } \\
\text { o }\end{array}$ & $\begin{array}{l}\text { Tingkat } \\
\text { keterbacaa } \\
\text { n }\end{array}$ & Jumlah & $\begin{array}{l}\text { Presenta } \\
\text { se }\end{array}$ \\
\hline 1 & Tinggi (3) & $\mathbf{1 6 4}$ & $\mathbf{9 9 , 4 \%}$ \\
\hline $\mathbf{2}$ & Sedang (2) & $\mathbf{1}$ & $\mathbf{0 , 6 \%}$ \\
\hline $\mathbf{3}$ & Rendah (1) & - & - \\
\hline Jumlah & $\mathbf{1 6 5}$ & $\mathbf{1 0 0 \%}$ \\
\hline
\end{tabular}

Pembahasan 


\section{Hubungan FTA dalam The Adventures of Sherlock Holmes dengan Teknik Penerjemahan Terhadap Kualitas Terjemahan}

FTA "bertanya" $\rightarrow 55$ data $\rightarrow$ ditandai dengan kata tanya $\rightarrow$ padanan lazim $\rightarrow$ terjemahan akurat, 1 data tidak akurat (got it= mendapatkannya), kurang berterima(expenses=biaya pengeluaran), dan terbaca.

FTA “mengeluh" $\rightarrow 14$ data $\rightarrow$ ditandai dengan penggunaan kata: but, if, cannot, no dan idiomatic expression $\rightarrow$ variasi $\rightarrow$ terjemahan akurat, 1 data tidak akurat $(128$, kreasi diskursif) beberapa data kurang berterima, dan terbaca.

FTA "mengancam" $\rightarrow 11$ data $\rightarrow$ frasa "there is no, there is no use, you'll be on fire" $\rightarrow$ adaptasi, padanan lazim, kompresi linguistik $\rightarrow$ menghasilkan terjemahan yang akurat, berterima, dan terbaca.

FTA "meminta" $\rightarrow 9$ data $\rightarrow$ variasi, padanan lazim.

FTA "memerintah" $\rightarrow 10 \quad$ data $\rightarrow$ get $\quad$ away, get $\quad$ back,dll $\rightarrow$ transposisi, adaptasi $\rightarrow$ terjemahan akurat, berterima, dan terbaca.

FTA “menolak" (refusing) $\rightarrow 10$ data $\rightarrow$ cannot, could not, shan't, impossible $\rightarrow$ padanan lazim, variasi $\rightarrow$ terjemahan akurat, berterima, dan terbaca.

FTA "menjawab" $\rightarrow 8$ data $\rightarrow$ padanan lazim $\rightarrow$ terjemahan akurat, berterima dan terbaca.

FTA “memperingatkan" $\rightarrow 7$ data $\rightarrow$ must not, will not $\rightarrow$ kreasi diskursif, amplifikasi (your filthy hand $=$ tanganmu yang kotor itu) $\rightarrow$ kurang akurat, kurang berterima dan terbaca.

FTA “meminta maaf" $\rightarrow 6$ data $\rightarrow$ sorry $\rightarrow$ adaptasi $\rightarrow$ akurat, kurang berterima (016), dan terbaca. 
FTA “mengejek" (mocking) $\rightarrow 6$ data $\rightarrow$ variasi, amplifikasi, adaptasi $\rightarrow$ terjemahan akurat, berterima, dan terbaca.

FTA “menyangkal" $\rightarrow 5$ data $\rightarrow$ no, nothing $\rightarrow$ padanan lazim, adaptasi $\rightarrow 1$ data tidak akurat(adaptasi), berterima, dan terbaca.

FTA "berjanji" $\rightarrow 5$ data $\rightarrow$ swear, promise $\rightarrow$ padanan lazim $\rightarrow$ terjemahan akurat, berterima dan terbaca.

FTA “menghina" (insulting) $\rightarrow 4$ data $\rightarrow$ harfiah(idiomatic expression), variasi, padanan laim, amplifikasi $\rightarrow 1$ data kurang akurat dan berterima, dan terbaca.

FTA “menantang" $\rightarrow 3$ data $\rightarrow$ padanan lazim, amplifikasi, reduksi, adaptasi $\rightarrow$ akurat, 2 data tidak berterima, dan terbaca.

FTA "memohon" $\rightarrow$ padanan lazim, amplifikasi dan transposisi $\rightarrow 2$ data akurat, 2 data kurang berterima, dan terbaca.

FTA “menolak" (rejecting) $\rightarrow 3$ data $\rightarrow$ amplifikasi, kompresi linguistik $\rightarrow$ akurat, berterima, dan terbaca.

FTA "meledek, menyesal, memaksakan kehendak, mengumpat dan mengundang" $\rightarrow 1$ data $\rightarrow$ amplifikasi, adaptasi, padanan lazim $\rightarrow$ terjemahan akurat, berterima dan terbaca.

\section{SIMPULAN}

Dari 165 data yang terkumpul menghasilkan 21 temuan jenis FTA: bertanya, mengeluh, mengancam, meminta, memerintah, menolak (refusing), menjawab, memperingatkan, meminta maaf, mengejek (mocking), menyangkal, berjanji, menghina (insulting), menantang, momohon, menolak (rejecting), meledek, menyesal, memaksakan kehendak, mengumpat dan mengundang. 
Data tersebut diterjemahkan dengan 15 teknik penerjemahan: padanan lazim, variasi, reduksi, amplifikasi, adaptasi, transposisi, peminjaman murni, kreasi diskursif, kompresi linguistik, modulasi, kompensasi, generalisasi, harfiah, peminjaman naturalisasi, dan amplifikasi linguistik.

Teknik yang memberi dampak positif pada tingkat keakuratan: teknik padanan lazim, amplifikasi, reduksi, peminjaman murni, kompensasi, adaptasi, dan kompresi linguistik. Teknik yang memberi dampak negatif: teknik harfiah dan kreasi diskursif

\section{SARAN}

\section{Penerjemah Novel}

Bagi penerjemah novel, khususnya novel detektif yang memuat banyak mengandung tuturan mengancam muka negatif dituntut untuk mampu memilih teknik penerjemahan yang mengutamakan keakuratan dan kelengkapan informasi agar pesan dalam BSu dapat dipahami oleh pembaca karena tidak semua pembaca memiliki latar belakang, budaya, dan keilmuan yang sama. Penerapan teknik harfiah dan kreasi diskursif dinilai banyak memberi kontribusi negatif pada kualitas terjemahan.

\section{Peneliti Lain}

Penelitian terjemahan kalimat yang mengandung tuturan mengancam muka dalam The Adventures of Sherlock Holmes karya Sir Arthur Conan Doyle ini dapat dikatakan masih memiliki banyak ruang penelitian yang bisa dijadikan bahan dan pengembangan penelitian selanjutnya. Penelitian sejenis masih dapat dikembangkan pada sumber data lain atau seri Sherlock Holmes yang lainnya. Dalam hal sumber data dalam penelitian ini masih memiliki beberapa celah untuk bidang penerjemahan lainnya dengan pendekatan pragmatik, seperti tuturan mengancam muka positif lawan tutur beserta 
responnya, kesantunan positif dan kesantunan negatif mengingat kumpulan cerita ini memuat porsi tuturan yang jauh lebih besar dibanding narasinya.

\section{DAFTAR PUSTAKA}

Austin, J.L, 1955. How to Do Things with Words. Oxford: Oxford University Press.

Brown, P \& Levinson, S.C. 1987. Politeness: Some Universals in Language Usage. Cambridge. Cambridge University Press.

Molina, L \& Albir, A.H. 2002. Translation Technique Revisited: A Dynamic and Functionalist Approach. Meta: Translator's Journal, Vol.XLVII, No.4.

Nababan, Nuraeni \& Sumardiono. 2012. Pengembangan Model Penilaian Kualitas Terjemahan, Laporan Penelitian Hibah Kompetensi. Surakarta. Universitas Sebelas Maret.

Nida, Eugene A. dan Charles R. Taber. 1982. The Theory and Practice of Translation. Leiden: E. J. Brill.

Searle, John R. 1969. Speech-Act. An Easy in The Philosophy of Language. London: Cambridge University Press.

Sutopo. H.B. 2002. Metodologi Penelitian Kualitatif: Dasar Teori dan Terapannya dalam Penelitian. Surakarta: UNS Press. 